\title{
Cultural Economy Utilization between the Reproduction of Handicrafts, Tourism and Capitalism: The case of Esna.
}

\author{
Amr Al Qamary ${ }^{1}$ and Yssmin Bayoumi²
}

\begin{abstract}
The cultural 'product' is a reproduction of a life style that was once born out of localized, temporal needs where people of the Nile valley utilized resources that they can reach to address these needs aligned with the societal context. This paper aims to examine the approach of cultural tourism reproduction in Upper Egypt and questions the current models for cultural economy and questions their alignment with current societal context.

The paper discusses the contradictions between tourism growth models, and sustainable local development along capitalistic exploitation potentials. It studies the interventions proposed/going-on Esna city center and possible development scenarios within the Egyptian context. The different approaches to utilize community crafts and the cultural economy within the city center are explored and critically analyzed for their alignment with local community sustainable development.
\end{abstract}

\section{Keywords:}

Crafts, Sustainable tourism, Socioeconomic, Cultural tourism.

\section{Introduction}

While most admired physical artifacts and constructions respond to ruling class and hegemonic stratum, some traces remain for normal traditions, daily activities and production routines of the majority. The wide scope of cultural tourism admires the latter. But what would happen if these cultural activities are forcefully reproduced just for tourism profitability? What if they no longer relate to the localized needs or resources? What if this cultural 'product' is mainly desired by the global explorers who seek to experience ancient ways of living?

The reproduction of such activities can bring valuable 'foreign income' to those who may perform these activities, or those who hire them. Such a change in economic model changes 'cultural-life-style' cycle which exploits and deforms original reproduction cycles.

Esna city center has various historical elements of hegemonic heritage; Khnum temple of ancient Egypt, Wekalet El Geddawy and El Emary Minaret of Islamic Egypt. The paper highlights the intangible history of crafts and activities in the city center and explores their potential economic cycles, specifically the ancient oil-mill (El Ma'sara), textile weaving and wooden production. Reflections and comparisons on Luxor development model and previous interventions proposals to Esna will be overlaid with crafts development models while considering the formation of the new generations' ideology with a criticism to the possible exploitation of the 'cultural product' that can hollow out the cultural activity from its stats of appropriating resources to the service of local community, and to the service of foreign communities.

In the first part, the paper reviews the growth of tourism and different models that support it. The models are contrasted with the evolution of tourism approaches and specifically cultural tourism with reflections on sustainable tourism and sustainable development, in addition to questioning if these approaches really reflect on local development and how all of that reflects on Egypt and Esna city. In the second part an introduction on Esna city was given with a layout on the path-shaping decisions and effects that helped in producing the current situation. The tourism model that is mostly evident in the city was presented accompanied with the noticed socioeconomic change within the city community. Different development plans were put into comparison together and with the different tourism models with a focus on the crafts existing in the city center which are wood carving, textile weaving and the old oil mill.

\footnotetext{
${ }^{1}$ Independent Urban Researcher

${ }^{2}$ Founder of Cell and Herfa initiatives
} 


\section{The growth of tourism}

Tourism is mainly connected to free time and leisure, but it also associates to travel, study, health, and religious activities in a wider definition by the World Tourism Organization (WTO). Tourism economy started to boom from the 1950s all through the way till today (Figure 01). One of the main drivers for this growth is the institutionalization of working labor right to leisure time through paid leaves. That caused an influx in demand which created a huge market that needed a huge supply, and 'mass' tourism in a fordist model was the way to organize the supply ${ }^{3}$.

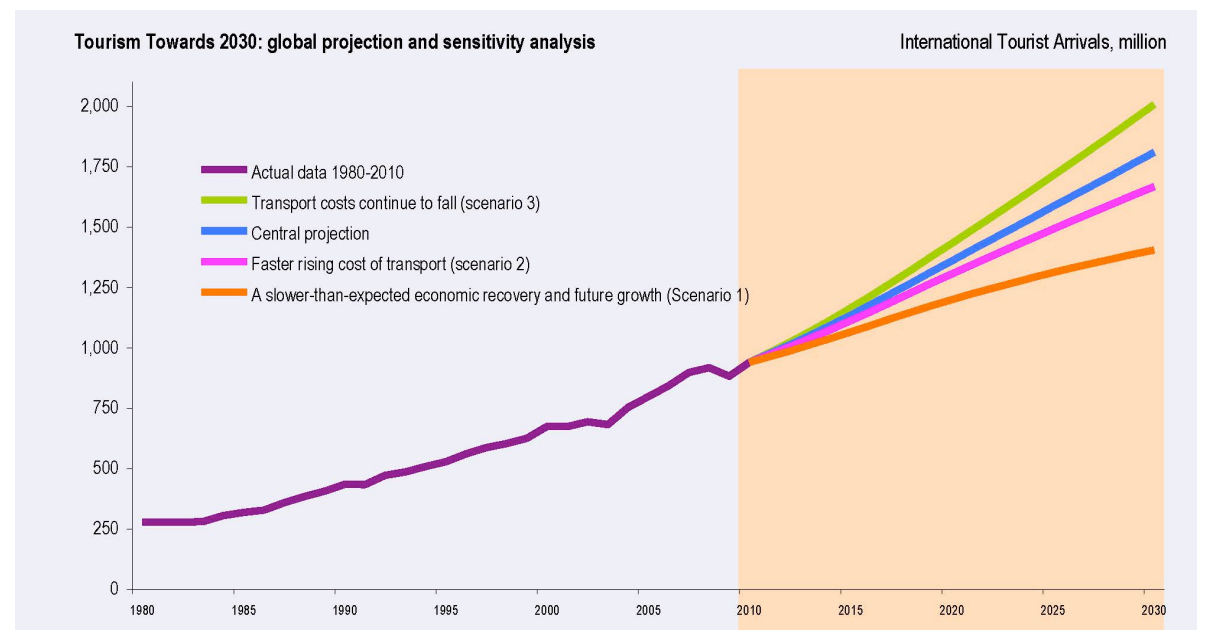

Fig. 1: Growth of Tourism, World Tourism Organization (UNWTO). (UNWTO2011)

Fordist models came with flexible packages, pre-decided routes, schedules, and pre-organized activities. It was safer with various options, indeed safer than self-organizing a travel-before the internet-. In addition, packages were the cheaper option; mass demand with mass supply and competition that helped in providing that ${ }^{4}$. When one is weighing travelling with a group of similar background, similar language and prepared tours that offer familiar services with familiar quality of food against travelling with an ambiguous self-developed plans, one would opt for the former.

\section{Development and tourism}

Multiple models can relate communities' development to tourism like growth pole theory, multiplier effect and export-base theory. Growth pole theory assumes that when a specific place succeeds to attract developments, nearby places would borrow its success; make use of the pool of demands attracted next to it and start development. On the other hand, the multiplier effects theory assumes a wide circulation of income; a single purchase in the market initiate a chain of activities (a meal in a restaurant will be accompanied by transportation activities, raw materials purchasing, cooking, cleaning, servicing, etc...). Export-base theory assumes the influx of foreign currency into the region as tourists come to purchase local goods and services ${ }^{5}$.

These theories do not fully explain development patterns; starting from valuable public resources that come to be allocated as incentive for 'big' investments related to tourism or in touristic infrastructure at the expense of locals needs, to the point where the cycle runs and most of the profits made by investors are reinvested elsewhere and not in the region.

The fordist model in a way contradicts with the previous development models. The specific routing reflects on a specific growth field, nullifying the growth pole theory in that scenario. Small and medium businesses are not really targeted by the bulky demand of mass tourism. If local production is not sufficiently developed to meet tourists quality expectations, a negative multiplier effect is triggered; where the majority of goods and services (furniture, construction materials, equipment, fancy food

\footnotetext{
${ }^{3}$ Dennis R. Judd, Lily M. Hoffman and Susan S. Fainstein , Cities and Visitors: Regulating People, Markets, and City Space. New Jersey: Wiley-Blackwell, $2003,187$.

${ }^{4}$ José Antonio Donaire Benito and Núria Galí Espelt, “The social construction of the image of Girona: a methodological approach.” Tourism Management, 2005: 777-785.

${ }^{5}$ Jayaprakashnarayana Gade and Raghu Ankathi. Tourism Management Philosophies, Principles and Practices. Hyderabad: Zenon Academic Publishing, 2016, $140-142$.
} 
and beverages, and even souvenirs) get imported offsetting the export revenue. This also reflects on the skilled employment positions that get its recruitment from imported labor, leaving only unskilled occupations (drivers, waiters, security, cleaning, etc...) for the locals.

However the main challenge which is not only related to Fordist model is the distortion in local market and local activities. Even though the employment opportunities would be unskilled and the public resources will be in the best case scenario split to address tourists needs with locals needs, locals would still find it profitable and can help them to 'raise their income' missing their development potential, where they abandon their traditional crafts and activities to work with this new unskilled jobs. This distortion can be laid within growth vs. development controversy, but sustainability of this change is what should be questioned.

\section{Sustainable tourism, Sustainable development and local development}

Regardless how un-sustainable tourism can be if the locals' environment is compromised, that was not the obvious objective of sustainable tourism. While the core approach to sustainable development as a concept is to fulfill society's current needs without negatively affecting future generation needs ${ }^{6}$, sustainable tourism approach in turn was as the type of tourism that serves current touristic needs in a way that preserves the rights of future tourists to access today's heritage ${ }^{7}$. The two can have contradictions; the preservation of an existing 'image' of a heritage can be mistaken as freezing the community dynamics in an open time frame and avoid/'fix' socioeconomic changes in the place. It attempts to make the community heritage 'static' and offsetting the dynamics to 'exported image' or exported product.

Similarly, wider definitions and approaches were developed to overcome such contradictions. Eber's approach to sustainable tourism is a much considerate definition. It emphasizes local resources both on social and environmental role in the strategic planning of a touristic site, as well as their right to have shares in the benefits.

"Addressing current and future needs through strategic planning, within the capabilities of touristic regions in a way that allows for resources renewal, recycling and production with contributions from local communities and consideration to their lifestyle which reflects on their share of economic benefits"

In our opinion, the attempts to overcome sustainable tourism and sustainable development contradictions lead to different tourism approaches including cultural tourism. It is not a new concept; in fact, it may represent the origin of tourism (i.e. tourists from Roman society visiting Greece or Egypt for cultural purposes).Cultural tourism attempts to re-emphasize the local activities and traditions in a way that can negate the distortion happening in local market and labor. One of the main strategies for it is the development of crafts and local activities through the simulation of original economic dynamics ${ }^{9}$. It attempts to brand local places by their intangible heritage, inherited traditions, crafts, local food and festivals.

According to The Organization for Economic Co-operation and Development (OECD), 2009, expenditure on cultural tourism was more than on any other types of tourism. The rise of Global Distribution System (GDS) and internet helped immensely in the rise of cultural economy. It also provided a window to override the dominant fordist model and challenge it. GDS and the internet provided individuals with access to information on the availability and prices to compare between flights, hotels, tickets and even packages.

It became easier for individuals to arrange their own trips, which was more aligned with cultural tourism concept. The local life experience was not that available with fordist limitation with group movement and pre-organized 'bubble'. However with Bed and Breakfast concept ${ }^{10}$ and individual tourism, the chance to blend in with locals' life and traditions is much higher. This helped to increase the locals' share in the supply side of tourism. GDS and internet is a communication bridge that shortened the distribution chain which facilitated an individual tourism model, which in turn provides an opportunity to align the purposes of tourism with local development to outweigh their contradictions.

However cultural tourism interventions are not always related to the tourism models, not in Egypt at all. 'Sustainable' tourism is supposed to be affected by seven important dimensions; environmental, cultural, political, economic, social, administrative

\footnotetext{
${ }^{6}$ Report of the World Commission on Environment and Development: Our Common Future, Oxford, WCED, $1987,41$.

${ }^{7}$ George McIntyre, Sustainable tourism development : guide for local planners. Madrid: World Tourism Organization, $1993,16$.

${ }^{8}$ Shirley Eber, "Beyond the green horizon: principles for sustainable tourism: a discussion paper commissioned from Tourism Concern." Godalming, Surrey : WWF UK (World Wide Fund for Nature), 1992, 53-54.

${ }^{9}$ Geoffrey Wall, “Is ecotourism sustainable?” Environmental Management, 1997: 483-491.

${ }^{10}$ Bed and Breakfast concept doesn't necessarily mean that breakfast is offered, Air BnB, house trip, etc...are known to provide accommodation with no breakfast.
} 
and institutional ${ }^{11}$. In Egypt, central political will and central institutional structure are the main drivers of the objectives and frameworks of development with an increasing influence of economic return on investments.

This leads to a biased reproduction, such as focused 'national' visions that leads to exclusive economic and administrative plans, causing some cities to develop over others (i.e. Luxor versus Esna). In addition, the central and security controlling mentality doesn't open a clear path for individual tourism model and it is more aligned with fordist model packages. These packages become the main driver for intervention types and locations; with emphasis on foreign desires that seek to find out about the ancient culture which hardly have traces to the previous couple of hundreds of years' dynamics. It is not how Egyptian heritage is branded, and the recent heritage is overwhelmed by the ancient heritage, which dominate touristic development schemes.

The development plans, then, focuses on external needs and requirements prioritizing the ancient heritage 'presentation', not only that but it allows for its economic dynamics to direct most of the income benefits to be central or corporate-wise oriented. Displacement and exclusion are usually the evident results of such strategies which help in the disappearance of local community with its culture, traditional crafts, food and social activities. The road of the sphinx in Luxor between Luxor temple and Karnak temple is a case in point where all people living above that newly-dug road were displaced and their houses demolished.

On the other hand, it is still quite difficult to fully work a cultural tourism intervention in Egypt. It is difficult to spread the individual tourism model or BnB economy. In all that vast heritage sites, a few traces of it can be found in Alexandria, Cairo, Hurgada, SharmAlSheikh, Dahab, and Luxor (Figure 02).
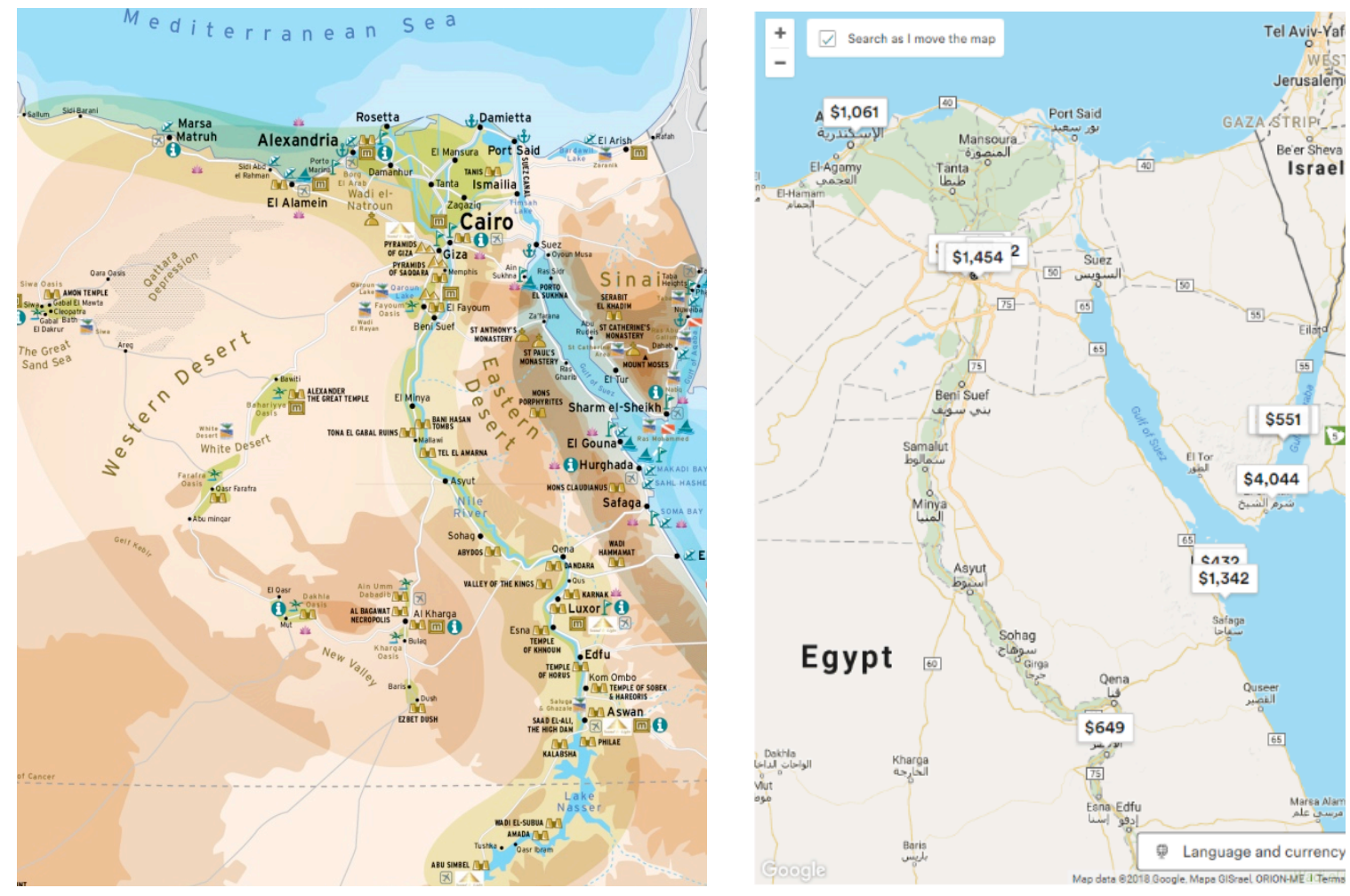

Fig. 2: Egypt tourism map and available AirBnB options in Egypt

Aside from the cultural tourism, the model followed in Egypt cannot even support Eber's wider 'sustainable' tourism approach. Egypt exports many of its souvenirs and many of modern/ fancy construction materials and furniture, which questions the development theories of multiplier effect or growth pole theory. It is a model that's only supported with export-base theory. Traditional society and craftsmen/women have undergone many distortions due to previous strategies, losing their development chances and niches to compete in both; the fordist model and the individual model.

\footnotetext{
${ }^{11}$ Ana Goytia Prat, Bill Bramwell, Greg Richards and Jan Van Der Straaten, Sustainable Tourism Management: Principles and Practice. Utrecht: Tilburg University Press , 1996, 19.
} 


\section{Esna City}

Therefore, Cultural tourism intervention in Egypt needs to be more comprehensive. Merely physical interventions with site management plans are not enough. Esna has been suffering a lot just from the ghost of invasive tourism development plans. Its city center has been frozen around the hegemonic existence of Khnum temple with a ban on renovation, maintenance, or reconstruction in a 25 and half Feddans around the temple area ${ }^{12}$. However, -in a way- this has helped in the preservation of the old city fabric and prevented concrete boxes development from happening. In this part we are going to explore the applicability of cultural tourism approaches that can align with local development in the city center of Esna.

Esna is located in between Luxor and Aswan in the south of Egypt (Figure 03). In the old administrative system, it used to be a directorate where Luxor was under its administration. Later, it followed Qena governorate before finally following Luxor governorate $\mathrm{e}^{13}$.

It is mostly recognized for Khnum temple and mostly branded by it; however the physical history extends to include Fatimid Emary Minerate and Wekalet El Geddawy. These buildings are mainly located in the old city (Esna city center). Guiding tourism websites are not doing Esna justice ( i.e. trip advisor or lonely planet), largely because of the mainstream branding of the above mentioned three buildings that do not weight much in a competition of a vast condense and various choices in Egypt itself.

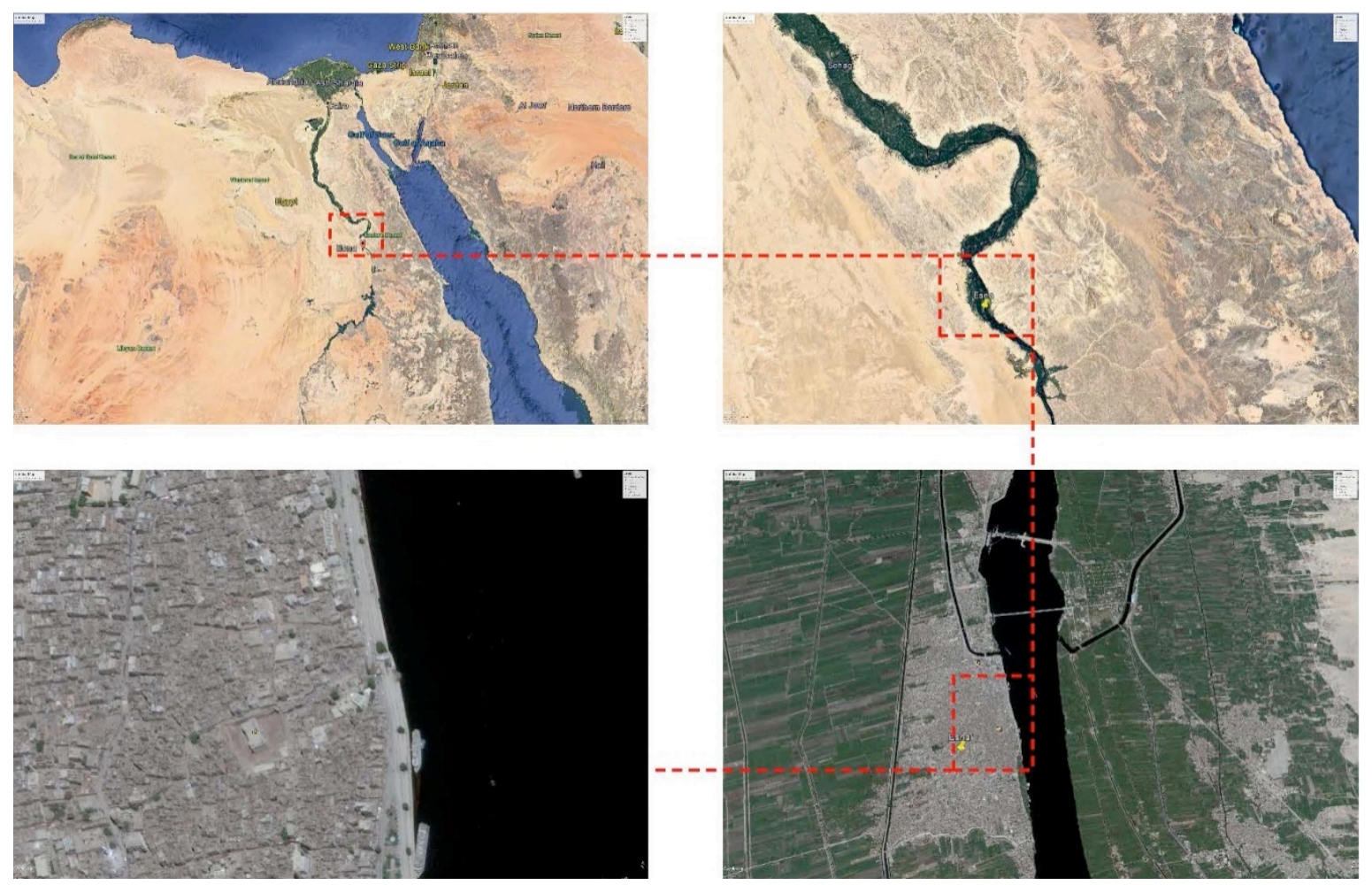

Fig. 3: Esna City center Location in Egypt map, from Google Earth

\section{Tourism Model in Esna}

Esna's cultural heritage is quite ignored. There is no proper valuation to the old commercial route and the urban fabric and typologies that grew around it within the context of an agriculture agglomeration. There is also very little focus on the ornamental work in the buildings and the prevailing wooden features in the architectural elements (Figure 04 \& 05).

\footnotetext{
${ }^{12}$ Samir Frag, Governmental Decision number 5133: Esna city municipality archives, Luxor government, 2012.

${ }^{13}$ Takween Integrated Community Development (TICD), Esna City Center Strategic Conservation Plan. Esna: ISDF, 2010.
} 


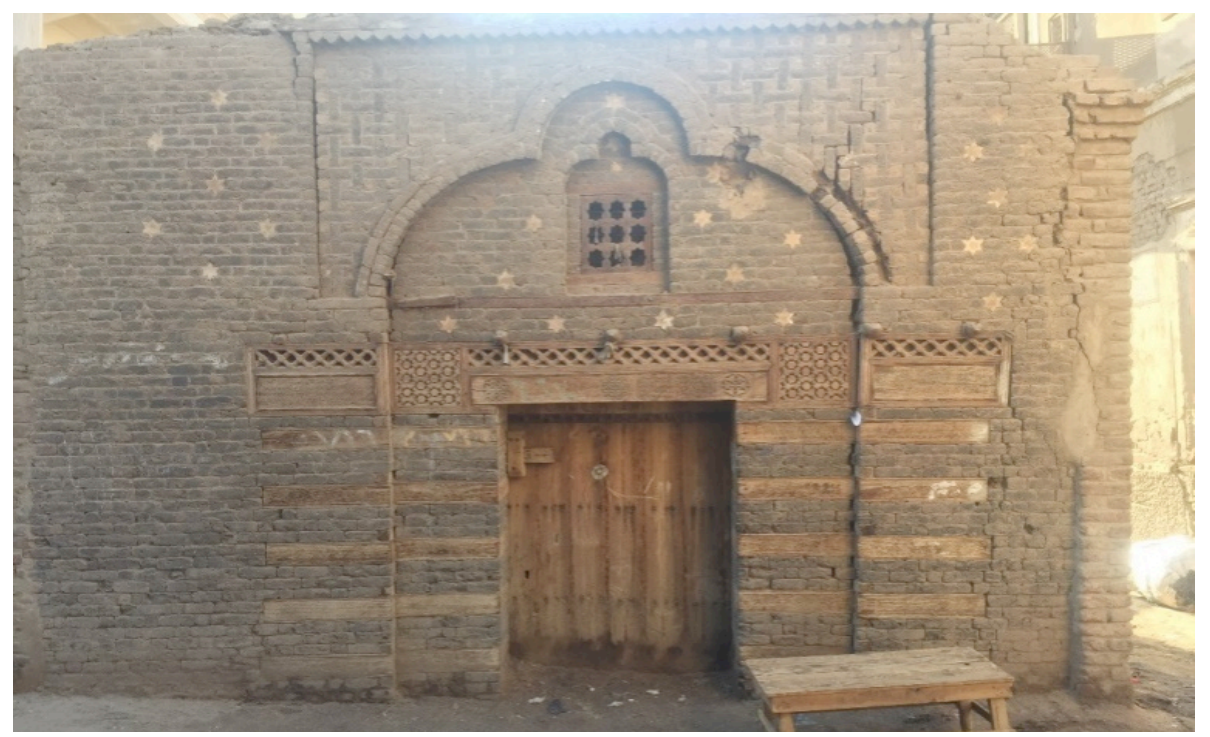

Fig. 4: lintel of traditional house stating the house construction and owners in Esna City, Bayoumi2017,Authors observation at Esna City, from August 2017 to October 2017

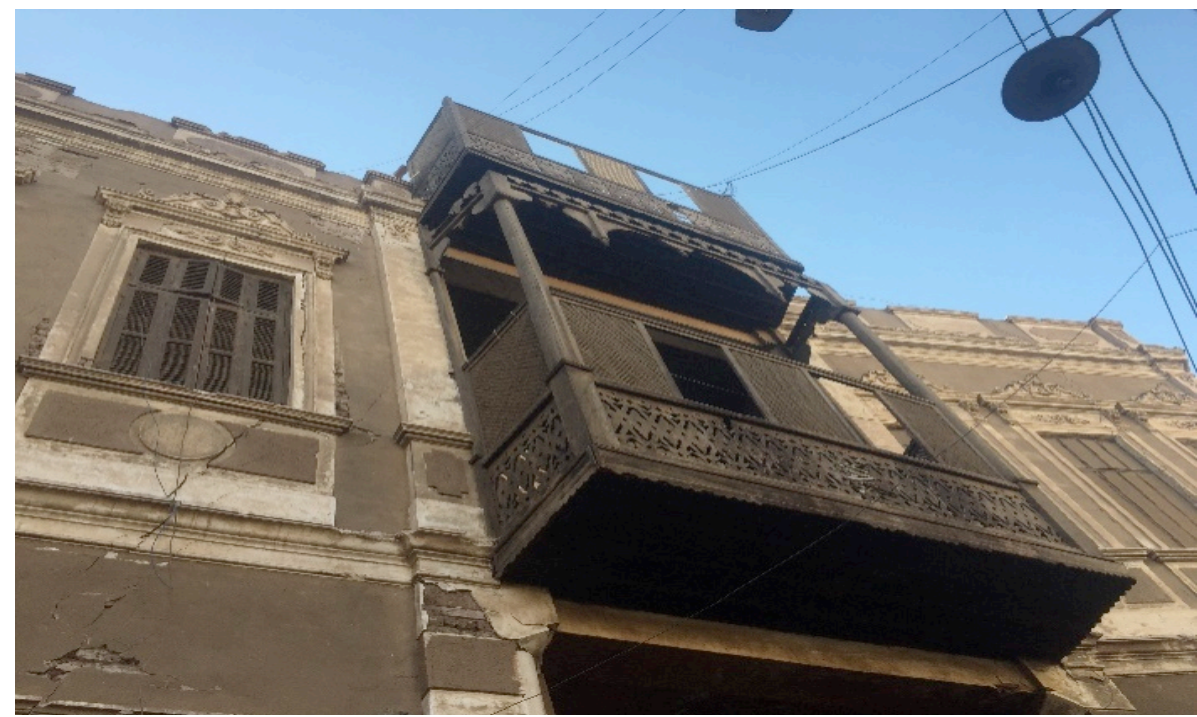

Fig. 5: Traditional house with typical balconies with Mashrabiya and wooden elements in Esna, ,Bayoumi 2017, Authors observation at Esna City, from August 2017 to October 2017

Cultural tourism approaches are difficult to achieve in Esna. This is largely due to the type of tourists that visit the city. They are only coming from cruises; there are hardly any tourists that come through buses or private cars, which is basically a type of a fordist tourism model. The tourist picks a package of places to visit in pre-organized routes. In addition, the cruises provide the meals and services for their guests, which doesn't give much need for restaurants or other services in the city. They spend a limited time in the center as per the schedule. 


\section{Socioeconomic changes}

In 2010 and according to tourism police department, only 13 out of three hundred cruises that go between Luxor and Aswan make excursions in Esna and only for couple of hours ${ }^{14}$. They can only visit Khnum temple and pass on the Emary Minaret, while Wekalet El Geddawy is closed for its deteriorated status. At the same time, some tour guides take the tourists to the old Oil Mill, which can be the initial built up point for a cultural tourism model.

Such a reality should not have disturbed the socioeconomic formation in the community. However that was not always the case; the stop time in Esna to sail through the old dam was a whole day, but that has changed after Esna new barrage was built in $1995^{15}$. That has disrupted the socioeconomic traditions.

In the city center there are two perpendicular commercial spines, both in meaning and geometry. The first is El-Htot street known as the tourists' market which became full of Bazars, and the other is El-Qisariyya Market which is the city old market that has used to serve (and still) domestic needs. Even though both decaying, Qisariyya market is much less vibrant and livable. Most merchandisers have opted to relocate in other vibrant parts of the city where they do not face as many hardships in any renovation/reconstruction efforts. In addition, many of the residents have followed the same pattern, the city center became hardly a quality place to live with all the decaying urban fabric; sewage network is still not working in the center till today.

It is said that Esna was a kind of shelter for exiled leaders of the country where they would come with a lot of expenses which helped in the growth of crafts in the city such as linen and cloth weaving out of cotton and wool and lettuce and sesame oil mills in addition to weekly and seasonal markets where diverse products would be put to sale ${ }^{16}$. Not so many crafts or cultural traditions can be seen as vibrant in the city at present. Only one Oil Mill remains in the city center while remnants of old parts of other mills seem to be scattered on the streets and within ruins. Some weaving and local cloth making can be seen within the old market premises.

\section{Locals Perception to intervention plans and tourism models:}

The locals link the main turning point for the deterioration of the city center to the 'twenty-five Feddans' freezing decision'. It is a decision mostly related to a development proposal by the Ministry of Housing, Utilities, and Urban Development (MoHUUD) that suggests the evacuation/ excavation and reconstruction of 25 Feddan around the temple proximity (nearly one thousand houses) ${ }^{17}$ (Figure 06).

Even though this decision was taken by Luxor governorate, the proposal in locals' perception is related to Ministry of Antiquities (MoA) as the main driver for such a decision. The project site is perceived to follow its administration. In addition, MoA would be the main governmental entity responsible for the displacement/reimbursements procedure. However, the only proposal related to MoA is only focusing on the temple extension in the west and entrance from the Nile in the east ${ }^{18}$ (grey area in figure 07).

However and in comparison to development interventions that were going in Luxor at the time, some locals were in favor for the mega intervention proposal by the MoHUUD. They perceive it as profitable according to what they see in Luxor. While the center is deteriorating either way, at least it is a step towards development.

The MoHUUD is more aligned with the tourism model in the city. It is very fordist; invasive, exclusive, appropriates locals resources of the many to benefit the few. However and due to the sociopolitical settings of the city and its location out of centrality, it is very difficult as well. Up until now, only the portion of houses in the area behind the temple where the remaining of it is expected to be located currently has a budget to reimburse the residents and take over their ownership. That took action only in the late 2017. In some parts of that proposal, 'a crafts' center would be mentioned but it is hollowed out of any authenticity of local traces ${ }^{19}$.

\footnotetext{
${ }^{14}$ TICD, 2010

${ }^{15}$ Mohamed Abu-Zeid, "Major policies and programs for irrigation drainage and water resources development in Egypt.” AGRIS, 1995, 33-49.

${ }^{16}$ Ali Mubarak, "Part 8: New plans for Egypt and its old and famous cities, Cairo, Amiri grand print house, 1887, 59-60.

${ }^{17}$ The Ministry of Housing, Utilities and Urban Communities. Shelter programmes and City Development Strategies in Egypt. Cairo: Thematic Committee, 2001.

${ }^{18}$ Pearce P. Creasman, Archaeological Research in the Valley of the Kings and Ancient. Vol. I. Tucson, Arziona: University of Arizona Egyptian Expedition, 2013.

19 “Rediscovering Esna Cultural Heritage Assets project." Integrated development as an approach for urban and cultural conservation in cities of Upper Egypt. Cairo: USAID, TICD, Supreme Council of Culture, 2017.
} 


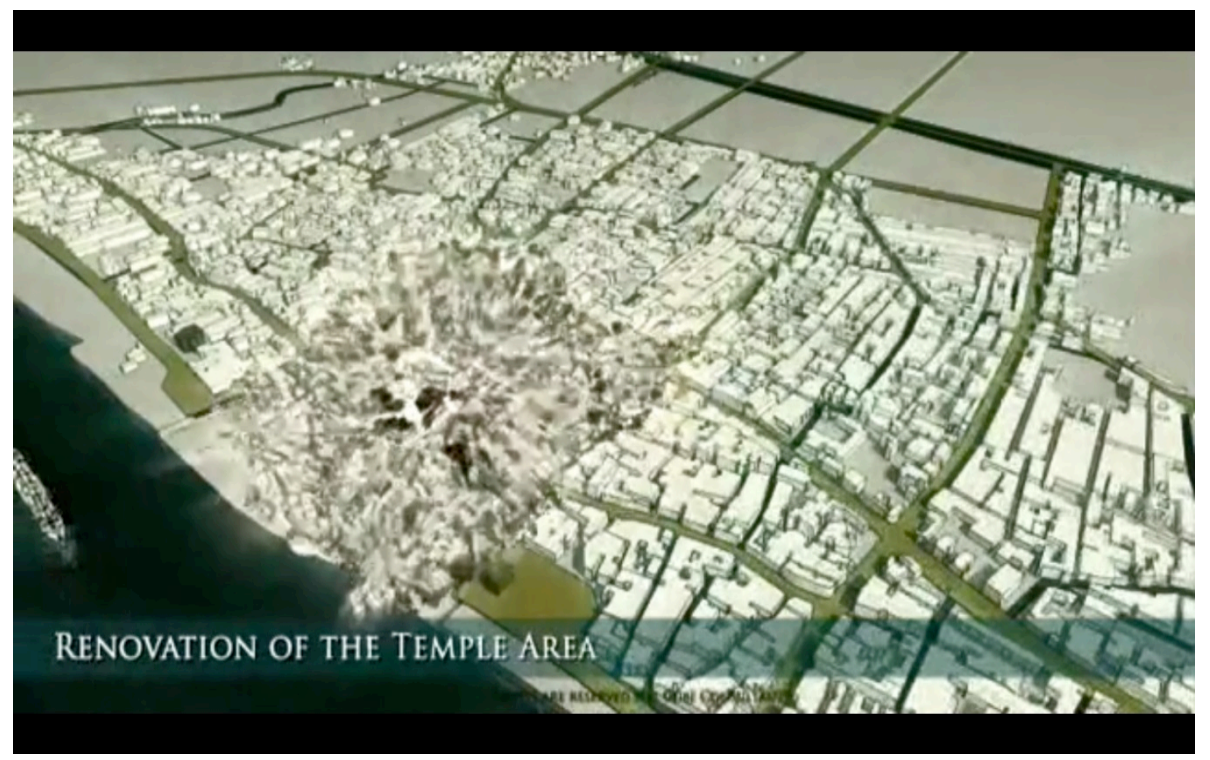

Fig. 6: Part of MoHUUD proposal, showing the 'explosion' of the old fabric to be replaced by a new desig, (CUBES 2010).
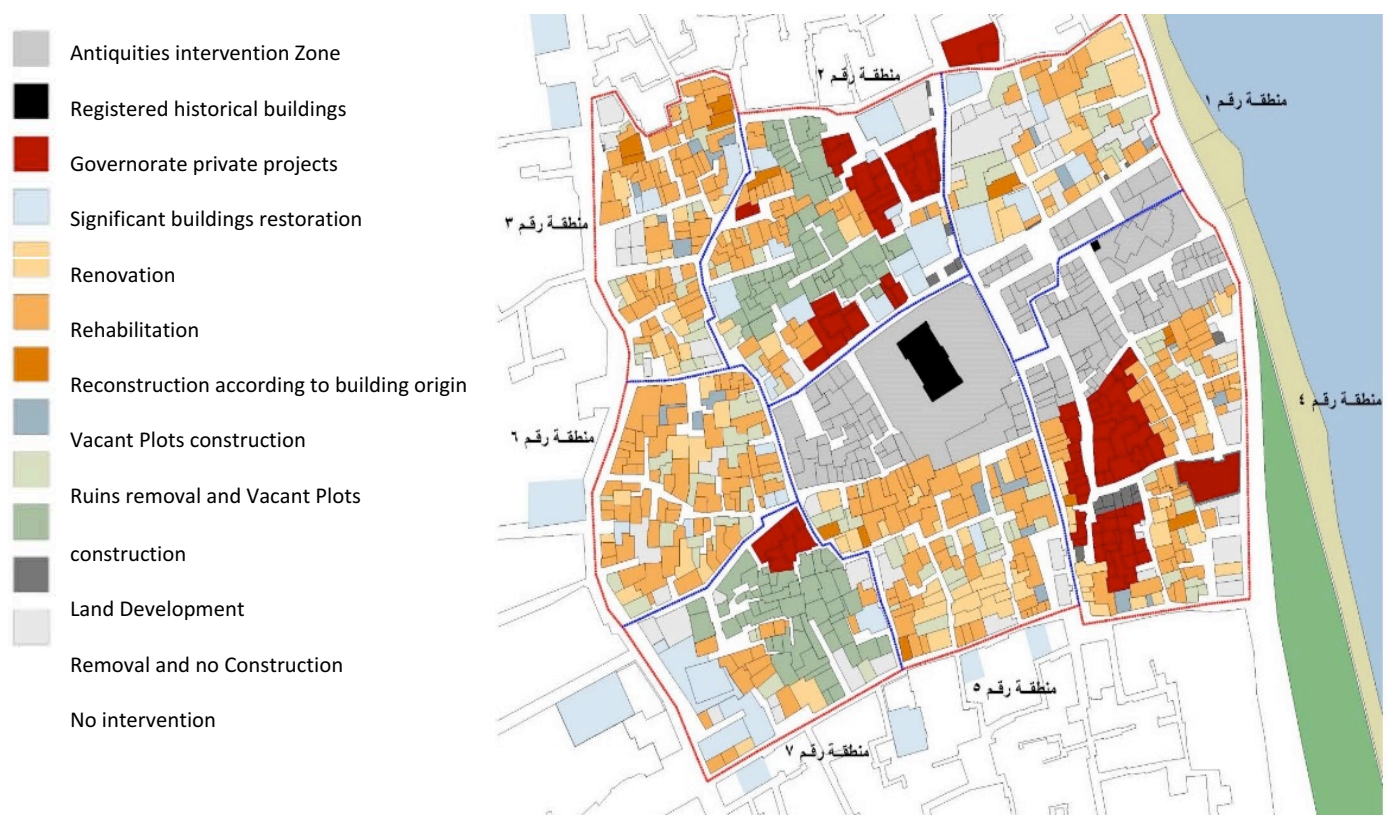

Fig. 7: ISDF intervention schematic plan, (TICD 2010)

The other competing proposal and less known one - as the former gained more publicity - is the Informal Settlements Development Fund (ISDF) (Figure 07). In the proposal was a study for the whole region and its socioeconomic structure that provided a tentative plan for tactical interventions to develop the center. The proposal is more aligned with cultural tourism concept, it emphasizes the local community and cultural assets. 


\section{Applicability of Cultural Tourism model}

Even though the ISDF proposal is more culturally oriented, it is not very aligned with the type of tourists that come to the city, nor its tourism model. If cultural tourism is to be developed, BnB economy and individual tourism model need to be developed in parallel within the city. Also the capacity of the local traditions and craft has been compromised over the years. However, the city center fabric and characteristics are still intact to express the culture along with old houses with their traditional materials and space layouts. If we are to divide the cultural 'touristic' product to physical and intangible, Esna physical cultural heritage is very promising, while the intangible activities and traditions are rather compromised.

Interventions strategies should focus on both aspects. One of the steps towards an inclusive development in 2017 was 'Rediscovering Esna Cultural Heritage Assets' (RECHA) project. It received fund from USAID lead by Takween Integrated Community Development (TICD) based on ISDF proposal in 2010 and in collaboration with Luxor governorate, MoA, and Ministry of tourism. The project includes these two components as soft and physical interventions. The physical part is the restoration of Wekalet El Geddawy, renovation of the public space in Qisariyya market and façade renovation of multiple significant buildings, while the soft part includes crafts training, capacity buildings programs and new branding strategies. The targeted developed crafts by the project are complementary products of textiles, souvenir, accessories, and art work, while the exported products are commodity products. The main crafts targeted in City center are textile, wood carving and Oil mill; the remaining targeted crafts are in nearby villages ${ }^{20}$.

\section{Scenarios of development}

This section presents possible scenarios for development based on the RECHA project orientation and cultural tourism objectives, in an attempt to layout favorable outcomes and their path in contrast to exploitation scenarios and their path with a focus on the Oil mill.

The challenges to reviving the sustainable/cultural dynamics are multiple including redeveloping craftsmanship skills, offsetting the employee market distortion, and providing a development horizon for craftsmen/women. This is in addition to the reproduction of the crafts cycle, and allocation of profits and personal development to the same place with a focus on avoiding centralization issues and individual capitalistic accumulation with negative multiplier effects.

In general, crafts development in decaying places usually starts with external resources with help of some local activists and community groups with efforts including training for different skills to cope with the new economic models of branding, marketing, packaging and products development and design. However, since trainers are external actors, they are oriented to external market needs which can be national/ international for it to find a place within external market requirements ${ }^{21}$.

The option to develop local market for the products is less likely to be explored since it may not be required, and since the focus is on tourism; inherently an external market. This gets affected by external investors who may be willing to invest in the targeted crafts, since locals usually have difficulties with funding resources and external investors find it as niche products for their recognized markets.

Such a structure can revive the craft, increase some specific craftsmen/women income, attract investors and develop a market, but it may not attach to the urban fabric or the place geography. As a result, it may not reflect on the local development, or the collective benefits which call for additional frameworks, efforts and conditions that should be devoted to integrate such important, essential aspects. Enriching the production model to have a parallel educational model can be an option for a better integration. This can promote the city center to have a creative tourism model as well, where tourists can co-live and co-produce products with the locals while learning the authentic crafts in the city. Even though this may be harder to achieve, as locals need a lot of training to be able to reach such state, but Voluntourism can be an initial stage to help with the locals' development ${ }^{22}$. The wood work and carpentry craft have higher chances of being integrated in the above mentioned aspects; the physical developments pursued in RECHA project focused on renovation and restoration will require local works and products. Successful restoration, revival and development will connect directly to the cultural image branding and local development success. Mashrabiyas - a type of projecting window enclosed with carved wood to ensure privacy -, balconies details, and lintels restoration can be replicated to really express the city crafts. It also has the potentials in national and international markets as well as local markets. It is a scalable activity in terms of labor market as well. While the high niche target will appreciate the handmade parts (which will cost more), the low niche market will compete through the automation of the craft and 3D printers (which may need huge investments in the beginning, can be monopolized, can be mass produced and cost less in addition to be

\footnotetext{
20 TICD, 2017

${ }^{21}$ Belinda Colston and David Watt, Conservation of Historic Buildings and Their Contents: Addressing the Conflicts. New York: Routledge, $2013,112$.

${ }^{22}$ Greg Richards and Julie Wilson, Tourism, Creativity and Development. London: Routledge, 2007, 62-64.
} 
made outside the city); a challenge that can be overcome by regulations and awareness. It will fit with Creative tourism and its teaching model will be both profitable and valuable to the local context.

Textile craft has lower chances, but it still connects to the local economy. The Habra, farkha products ${ }^{23}$ as well as 'Galabiyya' are local and traditional costumes and dressings of the community. It has some potential to penetrate national and international markets as well if it is engineered to be developed to suit other markets' needs. However, this will require some effort to offset any distortions/ price stratifications that may occur as a result of such new production. The same competition with industrialization and mass production can still develop, but can be overcome by the local appreciation for the authenticity of the products and supported by regulations. A teaching model through creative tourism can also enrich the craft, and present the production process as the main objective to experience and not just the product.

However, that is not the case for the Oil mill that was put out of business by the mass production of a needed commodity. It is mainly surviving now as a tourist's destination to visit and 'tip' its operator, an 80 years old named 'am Nasser who is the main fascination that one admires when going there. Fewer portions of the Oil Mill income comes from selling lettuce and sesame oil with some other types that are not covered by the mass industrial production.

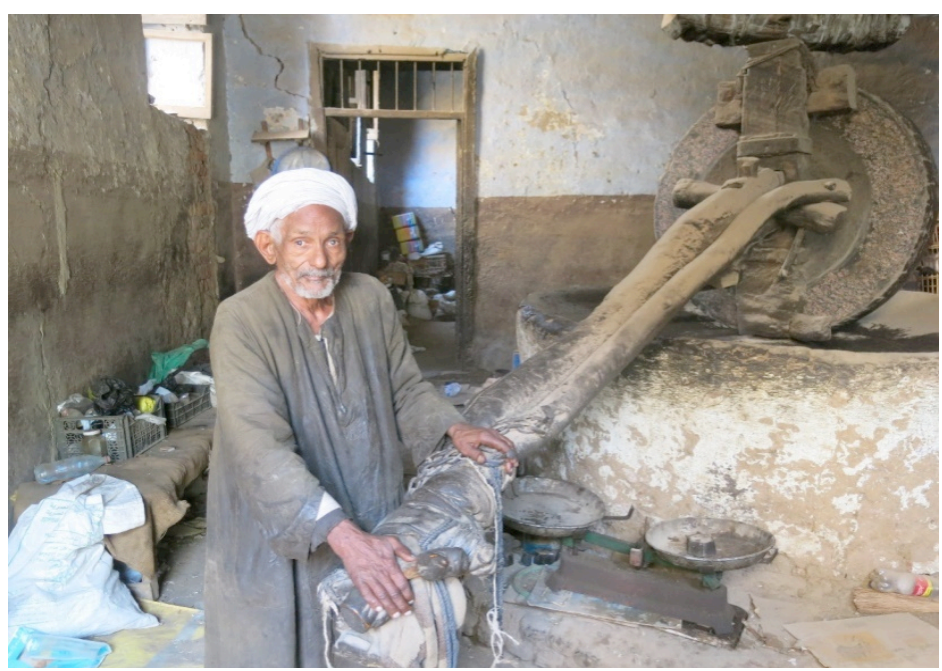

Fig. 8: 'am Nasser explaining how the old Oil mill works, Bayoumi 2017,Authors observation at EsnaCity, from August 2017 to October 2017

Inheriting the craft as a production activity does not seem as a valid or easy option. Most of 'am Nasser's family opt to work on something else, they do not see the benefits of making such a labor living on the possible tips of occasional visitors.

A common thing that may need to happen in all development scenarios is the renovation and cleaning up of the place. However, one scenario would go on renovating the places and emphasizing it as a 'historical artifact'; to change its use as a gallery for presenting old ways of pressing the seeds and the making of oil, which -in a way - turns it into a service economy that is more aligned with tourism in general and gives a static image of how this place was used and the kind of products it offered. It is a model that does not really offer any jobs or learning curves, rather it may need to be accompanied with some sales and marketing skills that does not much relate to a specific culture or tradition. ${ }^{24}$

It is a scenario that seems to express a 'cultural' site seeing, though it does not really represent a cultural or traditional dynamics; not anymore. It also will not offset any socioeconomic distortions that happened in the city, nor the economy disruption and dependability on foreign dynamics. The 2011 uprising and the tourism difficulties that came after all the unfortunate incidents have proven that economic dynamics should not be just dependent on external markets but integrated within local ones.

To carry on with such scenario, some external investors will need to be involved as the family does not have sufficient fund to do this renovation. Those investors will work on the marketing, rebranding and profiting from the Oil Mill, which will raise questions on who is really benefiting, where the profit is reinvested, and who is really learning the managerial and key skills. Models to develop the tradition itself are needed, as well as the different labor capacity to do so through all the production levels. Therefore, to restore the tradition and have the activity and dynamics of its production and development are the real

\footnotetext{
${ }_{23}^{23}$ TICD, 2017

${ }^{24}$ David J. Telfer and Richard Sharpley, Tourism and Development: Concepts and Issues. Bristol: Channel View Publications, 2014, 77-80.
} 
cultural products that tourists would like to see. Within this small part of the whole, remains a physical and intangible part. The renovation of the place and restoration of the production image alone is very shallow and it only aims to export the image of the tradition and samples of its production, where there should be training programs similar to the carpentry woodwork for the craft of producing natural oil, products development research workshops, and exploring horizons for development of the craft within the competing manufacturing industrial market. The product should undergo development stages similar to the image development stages, where both together are exported/ presented to tourists ${ }^{25}$. Both Voluntourism and Creative tourism can have big roles in such a strategy, and in the best case scenario its initial funding can be through grants. If successful, then it can be a scalable craft with a bigger footprint that would restore a cultural dynamics to a city tradition rather than remnants of a static painted old mill with minimal impact on the socioeconomics and traditions of the city.

\section{Conclusion}

Not all tourism models support cultural tourism concept. A comprehensive strategy should consider tactical restructuring and reforms in the dominant model followed in a place to enable a true revival of historic centers' tradition and livability. Individual tourism model seems to be much more appropriate for it and should be developed and regulated further in Upper Egypt. It may be one of the ways to supplement other types of tourism than cruise tourism.

However; true development needs much more effective coordination between different governmental entities. As presented above, many contradicting proposals have been put forward which all had some effects on reality that not only caused confusion for locals but also for local authorities and how they would manage the built environment through that. Esna city center had three different proposals, where one gave a hegemonic top-bottom shadow of demolitions and reconstruction with a freezing assets decision and another struggle to conserve and restore reality which also started from a top-bottom procedure but seems to be more collaborative.

Esna potentials for cultural tourism applicability are high but challenging. The physical reconstructions and renovations have to be accompanied by intangible heritage revival and local capacity building. However, it has to go beyond the plastic restoration of a craft or a culture, and beyond the conservation of a mental static image perceived for it. Dynamics, objectives (singular and plural), and interrelations should be the main goal of intangible restorations.

Singular/small footprint accumulation as a singular objective or evident outcome should be just a point of entry with prioritizing of identity building, personal development and innovation that can scale and really reflect on the collective culture with the possibility of locally modernizing it. The restoration of around 150 meter old mill can be profitable and give an image of a cultural tourism, but the true cultural economy restoration go beyond that. Even though the word conservation may seem static, when it regards such socio-economic complex systems it is very dynamic; urban conservation is dynamics' conservation and not static one.

Following up with current development interventions and understanding their correlation with the surrounding context along with implications on the local community will be extremely insightful for the argument we are making here. In addition, further work should be explored on how to balance between dynamics restorations, as it implies change and conservation, as it implies static-status and how to achieve such dynamics restoration.

\section{Acknowledgements}

The Authors would like to express their Gratitude for European Module for Spatial Development and Planning team, and give credit to Flavia Martinelli and Constanza Parra for the insights on tourism models and development where we built our theoretical review upon. Also we would like to thank TICD for providing support on site and the information on their previous work.

${ }^{25}$ Alain Dubeyras, Adele Renaud, Greg Richards, and Hyunhwan Kim "The Impact of Culture on Tourism”. Paris : OECD, 2009. 54-60 


\section{Bibliography}

Abu-Zeid, Mohamed "Major policies and programs for irrigation drainage and water resources development in Egypt.” AGRIS, 1995, 33-49.

Benito, José A. D. and Núria Galí Espelt , “The social construction of the image of Girona: a methodological approach.” Tourism Management, 2005, 777-785.

Mubarak, Ali, "Part 8 of new plans for Egypt and its old and famous cities, Cairo, Amiri grand print house, 1887, 59-60.

Colston, Belinda, David Watt, Conservation of Historic Buildings and Their Contents: Addressing the Conflicts. New York: Routledge, 2013, 112.

Creasman, Pearce P., Archaeological Research in the Valley of the Kings and Ancient. Vol. I. Tucson, Arziona: University of Arizona Egyptian Expedition, 2013.

CUBES consultants. Esna City Center Proposal. Esna: Ministry of Housing, Utilities, and Urban Development, 2010 .

Eber, Shirley, ed. "Beyond the green horizon : principles for sustainable tourism : a discussion paper commissioned from Tourism Concern.” Godalming, Surrey : WWF UK (World Wide Fund for Nature), 1992, 53-54.

Frag, Samir, Governmental Decision number 5133 . Esna municipality archives: Luxor government, 2012.

Gade, Jayaprakashnarayana and Raghu Ankathi, Tourism Management Philosophies, Principles and Practices. Hyderabad: Zenon Academic Publishing, 2016, 140-142.

Goytia, Ana P., Bill Bramwell, Greg Richards and Jan Van Der Straaten, Sustainable Tourism Management: Principles and Practice. Utrecht: Tilburg University Press, 1996, 19.

Judd, Dennis R. , Lily M. Hoffman and Susan S. Fainstein, Cities and Visitors: Regulating People, Markets, and City Space. New Jersey: Wiley-Blackwell, 2003, 187.

McIntyre, George, Sustainable tourism development : guide for local planners. Madrid: World Tourism Organization,1993, 16.

Alain Dubeyras, Adele Renaud, Greg Richards, and Hyunhwan Kim “The Impact of Culture on Tourism”. Paris : OECD, 2009, 54-60

"Rediscovering Esna Cultural Heritage Assets project." Integrated development as an approach for urban and cultural conservation in cities of Upper Egypt. Cairo: USAID, TICD, Supreme Council of Culture, 2017.

Richards, Greg and Julie Wilson. Tourism, Creativity and Development. London: Routledge, 2007, 62-64.

Report of the World Commission on Environment and Development: Our Common Future, Oxford, WCED, $1987,41$.

Takween Integrated Community Development (TICD), Esna City Center Strategic Conservation Plan. Esna: ISDF, 2010.

Telfer, David J. and Richard Sharpley,. Tourism and Development: Concepts and Issues. Bristol: Channel View Publications, $2014,77-80$.

The Ministry of Housing, Utilities and Urban Communities, Shelter programmes and City Development Strategies in Egypt. Cairo: Thematic Committee, 2001.

TICD, Esna City Center Propsal . Esna: ISDF, 2010.

UNWTO, tourism highlights Report. Korea: World Tourism Organization, 2011.

Wall,Geoffrey, "Is ecotourism sustainable?” Environmental Management, 1997, 483-491. 